\title{
Comparison of PM and Hybrid Excited Machines for Marine Vessel Hybrid-Electric Propulsion
}

\author{
Mehdi Hendijanizadeh, Suleiman M. Sharkh and A. Ali Qazalbash
}

\begin{abstract}
This paper evaluates the maximum torque capability of a hybrid excited synchronous machine in comparison with a conventional PM synchronous motor. The main focus of the paper is on the study of the effect of DC excitation magnetic flux on the saturation of the stator teeth, which limits the torque production capability of the hybrid machine. Magnetostatic and transient analyses are carried out for both motors. As expected the hybrid motor air gap flux controllability comes at the expense of reducing its torque density. The torque density reduction penalty is quantified and some hidden limitations and challenges of designing such a hybrid motor are revealed based on an in-depth analysis of the flux distribution within the machine.
\end{abstract}

Index Terms-- Permanent magnet machine, torque, saturation magnetization, hybrid excitation, field weakening.

\section{INTRODUCTION}

$\mathrm{O}$ VER the last few years, especially after the Paris convection, which sets a target of keeping global temperature rise in this century well below $2^{\circ} \mathrm{C}$, more stringent restrictions have been applied or are due to be applied on emissions from boats and ships [1]. Many studies show that employing hybrid-electric propulsion in marine vessels can be a feasible solution for reducing emissions and fuel consumption [2, 3]. High level of maneuverability, reduction of fuel consummation, improving efficiency, reduction in noise and vibration, and compliance with new environmental regulations are some of the main motivation behind the development of hybrid-electric propulsion systems for marine vessels [4]. In this regard, the lessons learnt from hybrid-electric traction vehicles can be exploited in component selection and design of an appropriate hybrid system for marine applications.

The electrical machine operating in both generator and motor modes is a key component of a hybrid propulsion system. Specifications of suitable electric machines tailored for traction applications have been broadly discussed in the literature. Permanent magnet (PM) synchronous machines using a power electronic drive with a field weakening capability to enable operation in constant power mode over a wide speed range are used in many commercial hybrid vehicles. PM machines have the advantages of higher efficiency and smaller size in than induction, wound DC or switched reluctance machines, but at the expense of the high cost of the magnets. For this reason PM machines seem to

This work was supported in part by Innovate UK Technology Strategy Board: Marine Vessel Efficiency III Programme, Application Number 54530 - 405190: Hybrid Electric Vessel Propulsion with Integrated Motor Assist (HEVIMA). dominate the hybrid electric vehicle market, although other types of machine, induction in particular, are also used by leading manufacturers [5].

Learning from the road vehicle industry, PM synchronous machines are seen as strong candidates for hybrid-electric propulsion of marine vessels. However, unlike a hybridelectric traction vehicle which has a load curve exhibiting a wide constant power-speed range, a marine vessel's propeller power curve rises monotonically as the cube of the speed [6]. At first sight, this may suggest that the electric motor drive in a marine vessel may not need to have a field weakening capability. In practice, however, the operational and hence power demand profile of the vessel as well as space limitations may dictate the use of a motor of a certain size and torque. These constraints combined with battery power limitation may mean that the motor can only usefully assist up to a certain speed, typically around one third to half the maximum speed of the engine. Beyond that speed, it can operate in generator mode to charge the battery; in such a mode, it will be necessary to operate in field weakening mode to limit the generator's terminal voltage and avoid uncontrolled charging of the battery through the freewheeling diodes of the inverter. An alternative would be to reduce the motor's number of turns such that its rectified terminal voltage remains below that of the battery over the whole speed range, but that would mean oversizing the inverter to cope with the high motor current. Another alternative would be to say mechanically decouple the motor from the engine above base speed or use a variable gear ratio coupling between the engine and the motor. But all of these alternatives are more expensive than using a drive with a field weakening capability.

There is, however, a great deal of nervousness in the marine industry about relying on an electronic drive using field weakening in generator mode to limit the voltage to prevent uncontrolled charging of lithium batteries in particular, which may be the inevitable choice for efficient hybrid vessels [7]. Using say a dc circuit breaker or a fuse to disconnect the battery in such a scenario is not seen as a safe option. In lead-acid batteries, heat is generated by current flow and disconnecting them from the charging source ceases any thermal runaway. However, the electrolyte used in lithium-ion batteries is flammable and an exothermic reaction is more like an internal fire [8]. Hence, even after removing the charging contacts, the electrolyte may continue to burn on its own [9].

Mehdi Hendijanizadeh and Suleiman M. Sharkh are with the Mechatronic Research Group, University of Southampton, SO17 1BJ, United Kingdom (m.hendijanizadeh@soton.ac.uk, suleiman@soton.ac.uk).

A.Ali Qazalbash is working with industry as an electric machine design engineer (arfakhshand.qazalbash@gmail.com). 
An alternative is to use a wound field synchronous machine whose excitation can be safely controlled, or even completely disabled; its operating speed range is also wider and its efficiency at speeds higher than rated speed of machine can be better than PM machines due to efficient flux weakening control, but they have lower maximum efficiency than PM machines [10].

Hybrid Excitation Machines (HEM) combining PM and wound field machines have the potential to provide a more attractive solution for hybrid-electric marine vessels. Comprehensive reviews of HEM topologies are presented in [11-15]. By definition, a HEM is a type of machine that utilizes at least two excitation sources: the main common flux sources are PMs and excitation coils fed with DC current. In addition to their fail-safe field-weakening feature, reducing the amount of rare-earth magnet material is another motivation behind considering hybrid excitation machines [16].

This paper carries out a side-by-side comparison between a conventional surface mounted PM machine and a consequent pole hybrid excited machine. The main purpose of this study is to quantify the torque density reduction penalty when the main dimensions of two machines including the diameter of the rotor, slot depth and overall active length are the same.

\section{HYBRID EXCITATION MACHINES}

Hybrid excitation machines can be categorized based on different criteria. For instance, considering the magnetic flux paths for excitation sources, they can be divided into series hybrid excitation or parallel hybrid excitation types. In the series hybrid excitation type, the flux produced by the excitation winding passes through the PMs. Therefore, due to the low permeability of PMs, the excitation filed has a high reluctance path which limits the flux-adjusting capability of such machines. In addition, in this structure, PMs are at a risk of demagnetization. In contrast, parallel hybrid excitation machines have a short magnetic flux path and there is no PMs demagnetization threat [13-14].

With respect to the structure of the machine, they can be classified as 2D and 3D structures. Most of the investigated 2D hybrid machines are flux switching derived topologies [17, 18]. The 2D structure tends to limit the capability for applying hybridization ideas used in other machine topologies. Although 3D machines are more complicated in terms of analysis and manufacture, they allow the realization of a wide verity of machine topologies [15].

Also, depending on the location of flux sources, the hybrid machine can be categorized as having sources in the stator [19], sources placed in the rotor [20] or PMs in the rotor and excitation winding(s) in the stator $[21,22]$. In general, locating the excitation winding in the stator is preferable to avoid sliding contact problems such as slip ring maintenance and brush sparking.

One of the hybrid excited machine topologies proposed by Tapia et al. [21] is a consequent-pole permanent magnet machine. This machine can be categorised as a parallel hybrid machine with a $3 \mathrm{D}$ structure where the excitation winding is mounted within the stator. Fig. 1 shows a half symmetrical part

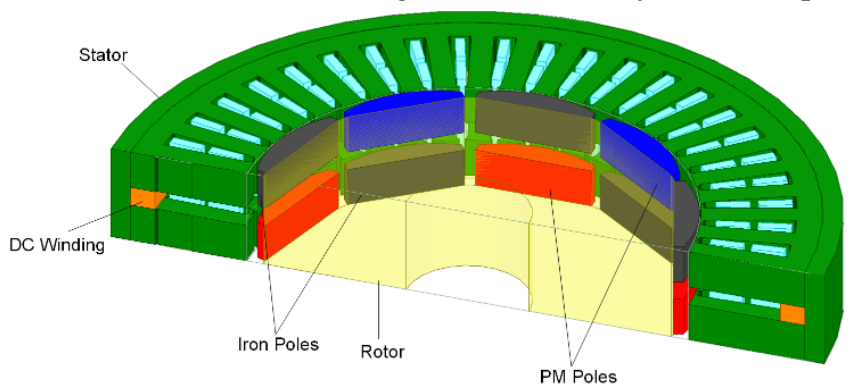

Fig. 1. Consequent pole hybrid excitation machine

of this machine which has a two-part rotor. Each part of the rotor has radially magnetized surface mounted PMs, and iron poles. The stator consists of a two-part laminated core with a circumferential excitation winding located in between. The stator structure is surrounded by a solid iron yoke, which provides a low reluctance path for the axial flux. By controlling the excitation winding current, the magnetic flux in the air-gap and consequently the EMF of the machine can be adjusted.

A simplified reluctance-based equivalent magnetic circuit of this machine is presented in [23], which is utilized to develop its design process. However, the magnetic circuit does not consider non-linear magnetizing characteristic of the ferromagnetic materials, which as will be seen later can have a significant effect on the performance of the machine.

\section{MACHINES DESIGN AND FEA ANALYSIS}

To compare both topologies, a $42 \mathrm{~kW}$ conventional surface mounted permanent magnet machine has been designed. A half cut of the machine is shown in Fig. 2 and its parameters are presented in Table I.

Fig. 3 shows the magnetic flux density in the conventional machine obtained using magneto-static finite element analysis (FEA). All the dimensions of the rotor, PMs, stator teeth and slots have been determined such that the magnetic field density in the ferromagnetic material does not exceed $B_{\text {sat }}=1.6 \mathrm{~T}$. The current density in the windings was set to be, $J_{\max }=13 \mathrm{~A} / \mathrm{mm}^{2}$ which assumes liquid cooling. In addition, the PMs have been shaped to reduce cogging torque.

As illustrated in Fig. 3 the thickness of the magnets and the width of the stator teeth have been selected such that the maximum flux density in the stator teeth and stator yoke is kept below the permissible limit of $1.6 \mathrm{~T}$. The no-load magnetic flux density in the conventional machine in the middle of the air-gap (at a radius of $179.5 \mathrm{~mm}$ from center) as a function of the angular position is shown in Fig. 4. It can be seen that the magnetic flux hits the amplitude of 1.3 T. Fig. 5 shows the no-load flux linkage per phase and Fig. 6 shows the line-to-line emf of motor when the speed is $4000 \mathrm{rpm}$. In this machine, the number of turns was selected such that the rectified no-load output voltage at rated speed remains below the DC-link voltage (the DC link voltage is $320 \mathrm{~V}$ in our case). Fig. 6 indicates a peak line-to-line voltage of $252 \mathrm{~V}$, which meets the design objective. 
TABLE I

PARAMETERS OF THE DESIGNED SURFACE MOUNTED PM MOTOR

\begin{tabular}{|c|c|c|}
\hline Parameter & $\begin{array}{c}\text { Conventional } \\
\text { Machine } \\
\text { Value } \\
\end{array}$ & $\begin{array}{c}\text { Hybrid } \\
\text { Machine } \\
\text { Value }\end{array}$ \\
\hline Number of poles & 10 & 10 \\
\hline Number of slots & 45 & 45 \\
\hline Winding layers & 2 & 2 \\
\hline Average coil pitch & 4 & 4 \\
\hline Total Core length & $26 \mathrm{~mm}$ & $40 \mathrm{~mm}$ \\
\hline Core active length & $26 \mathrm{~mm}$ & $26 \mathrm{~mm}$ \\
\hline Stator outer diameter & $283 \mathrm{~mm}$ & $290 \mathrm{~mm}$ \\
\hline Stator inner diameter & $180 \mathrm{~mm}$ & $180 \mathrm{~mm}$ \\
\hline Air-gap & $1 \mathrm{~mm}$ & $1 \mathrm{~mm}$ \\
\hline Inner rotor diameter & $50 \mathrm{~mm}$ & $50 \mathrm{~mm}$ \\
\hline Slot depth & $34 \mathrm{~mm}$ & $34 \mathrm{~mm}$ \\
\hline Slot opening & $2.2 \mathrm{~mm}$ & $2.2 \mathrm{~mm}$ \\
\hline Tooth width & $86 \mathrm{~mm}$ & $86 \mathrm{~mm}$ \\
\hline Tooth tip height & $1.1 \mathrm{~mm}$ & $1.1 \mathrm{~mm}$ \\
\hline Magnet thickness & $10 \mathrm{~mm}$ & $10 \mathrm{~mm}$ \\
\hline Pole offset & $40 \%$ & $40 \%$ \\
\hline Pole embrace & 0.88 & 0.88 \\
\hline Rated speed & $4000 \mathrm{rpm}$ & $4000 \mathrm{rpm}$ \\
\hline
\end{tabular}

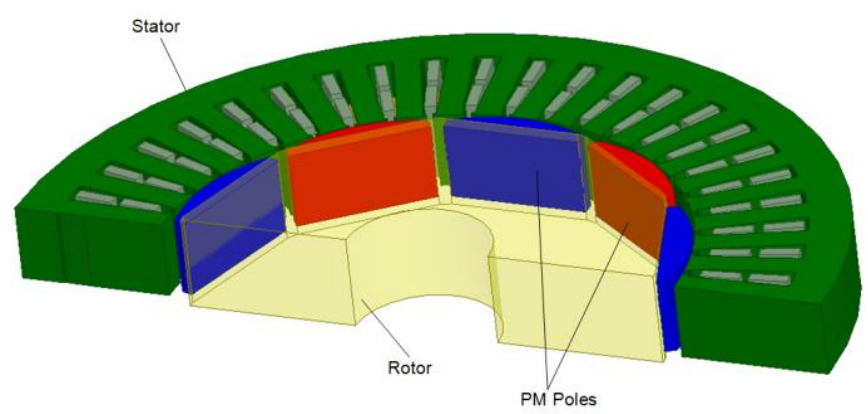

Fig. 2. Surface mounted PM motor

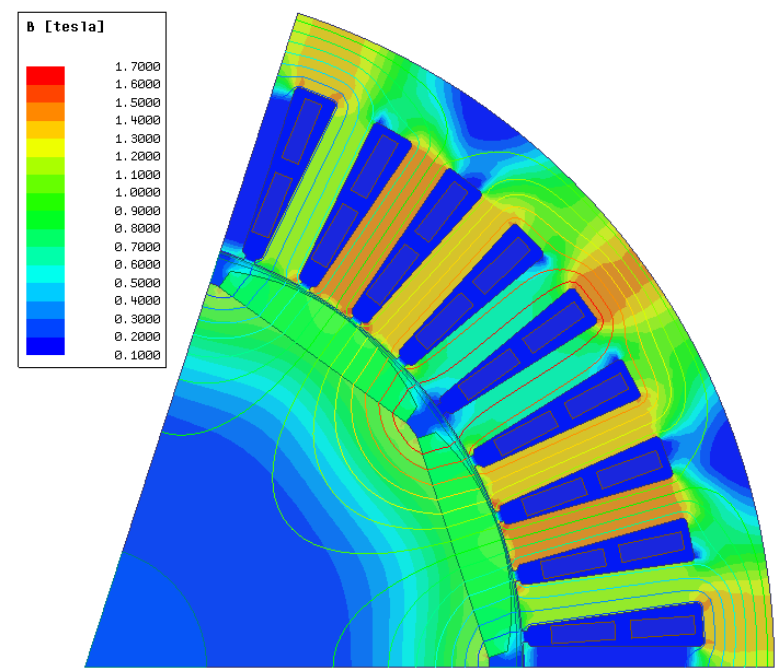

Fig. 3. Magnetic flux density distribution in the conventional surface permanent magnet machine.

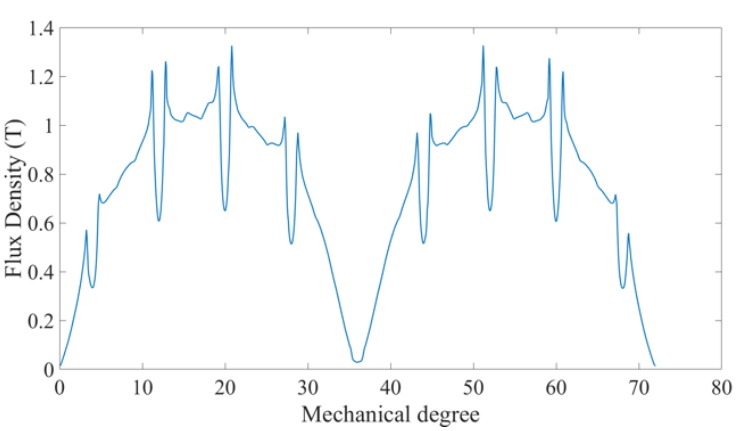

Fig. 4. Magnetic flux of conventional PM machine at the center of air-gap.

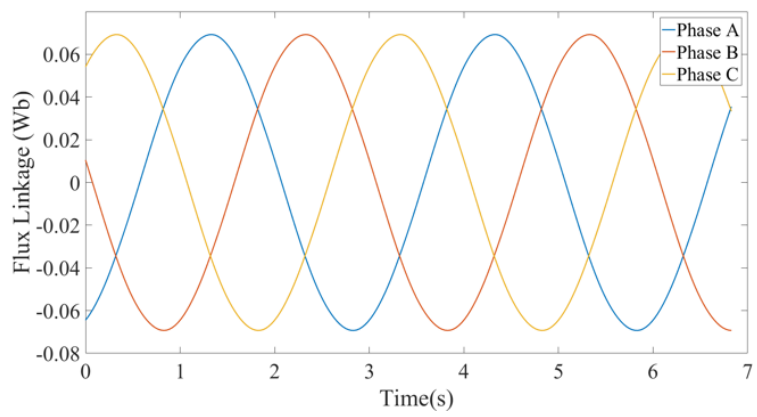

Fig. 5. Flux linkage per phase of the conventional PM machine.

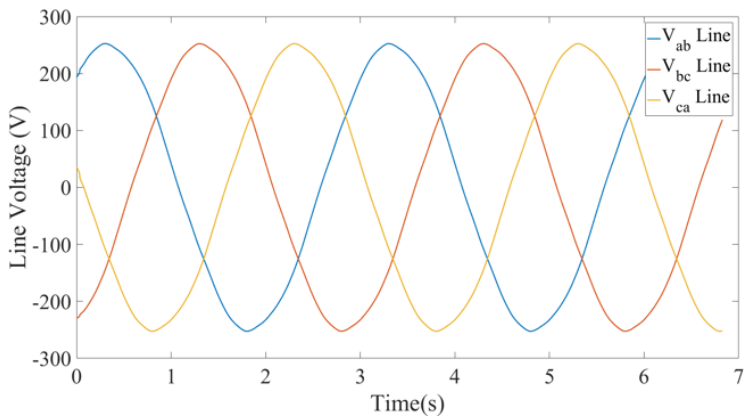

Fig. 6. Line-to-line emf of the conventional PM machine.

The hybrid machine structure, shown in Fig. 1, consists of a two-part rotor with an axial length of $13 \mathrm{~mm}$ each. There is a $14 \mathrm{~mm}$ gap between two sections. Accordingly, the width of the circumferential DC field winding is $14 \mathrm{~mm}$; its depth is 10 mm.

The stator yoke thickness of the hybrid machine has been selected so as to leave sufficient space for accommodating the DC winding and adequate steel material in the stator yoke to return the axial flux in the case that DC excitation winding is placed in the stator. Therefore, in the hybrid machine, the outer diameter of the stator is larger than the conventional machine. Other dimensions of the machine including magnet shape and height, inner stator diameter, rotor and winding configuration remain the same as the conventional PM machine. The parameters of this machine are shown in Table I.

Fig. 7 shows the 3D air-gap flux density of the hybrid machine for four different values of DC field current (0 Aturns to 1200 Aturns). The figures show the flux over two consequent poles as a function of angular and axial positions. As can be noted from the plots, by increasing the excitation 


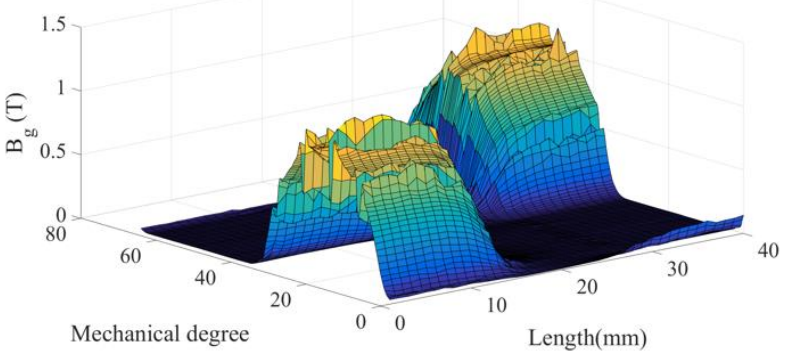

(a)

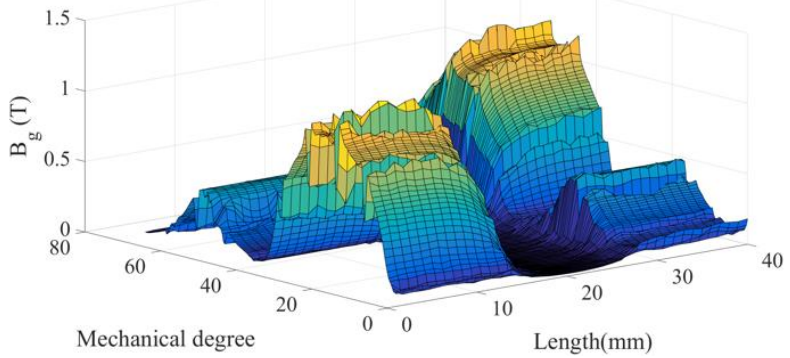

(b)

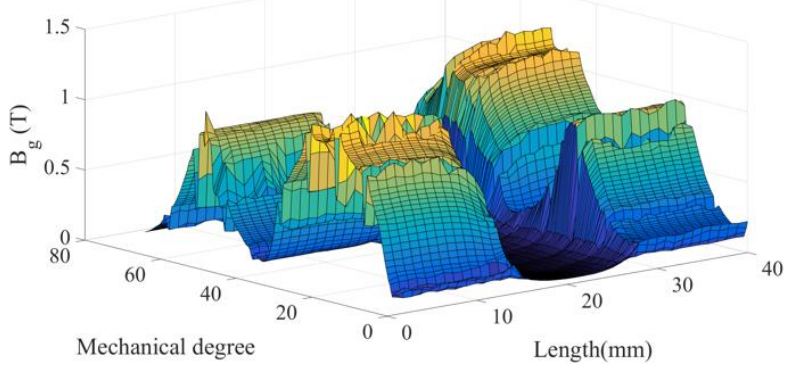

(c)

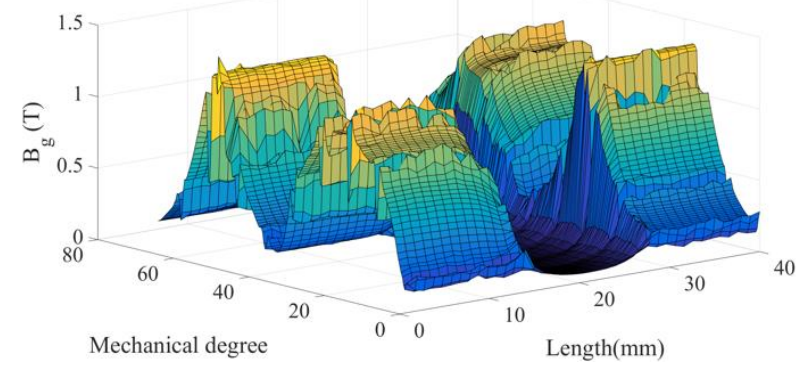

(d)

Fig. 7 Air-gap flux density distribution in the give over one pair of poles in the hybrid machine for different values of DC current: (a) 0A turns, (b) 400 Aturns, (c) 800 Aturns, (d) 1200 Aturns.

current, the magnetic flux due to the PMs does not change. However, the flux density magnitude due to the applied DC current magnifies in proportion to the applied current-turns. The slotting effect of the machine is also apparent from the four figures (14 mm slot gap). In this machine, the total flux in the air gap is the sum of the constant flux produced by the magnets PMs plus (or minus) the controllable flux produced by the field current.

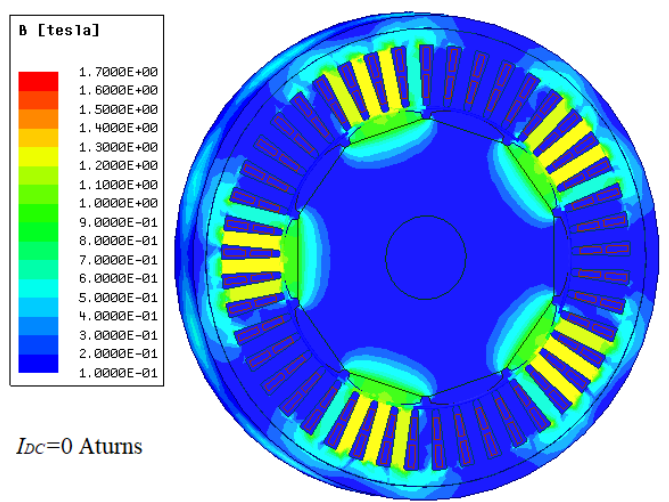

(a)

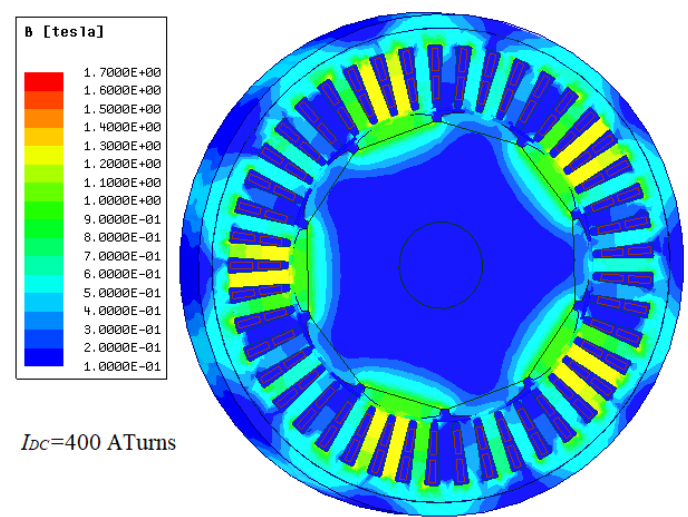

(b)

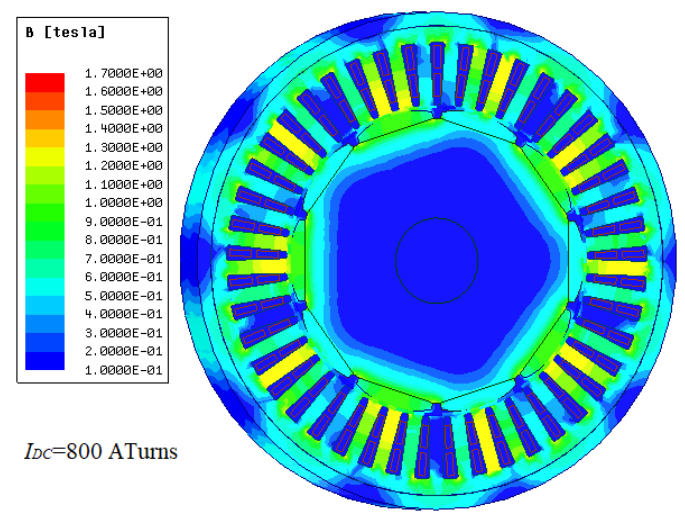

(c)

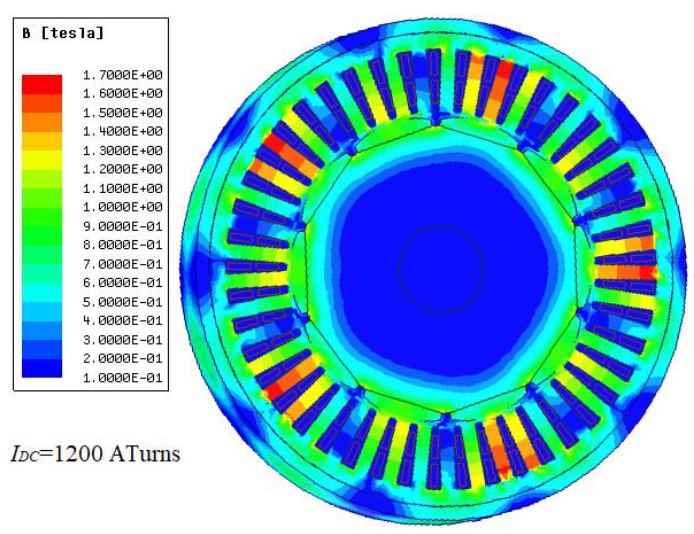

(d)

Fig. 8 Magnetic flux density distribution in the hybrid machine for different DC current excitation values. 
As the main purpose of this paper is to evaluate the maximum torque production capability of the hybrid machine, here, we only present cases in which the direction of the field current strengthens the air-gap flux. However, as discussed in [22, 24], the field weakening can also occur by changing the direction of DC current. Fig. 7 (d) indicates that by applying 1200 Aturns, the DC current excited air gap flux density rises to that of the of the PM flux. Considering a fill factor of 0.70 (using bus-bars to form the DC winding) 1200 Aturns corresponds to a dc winding current density of $J_{D C}=$ $12.3 \mathrm{~A} / \mathrm{mm}^{2}$ which assumes water cooling.

Fig. 8 shows the flux distribution in the hybrid machine for different values of excitation current. It can be seen that in the absence of DC excitation, the flux only arises from PM and mainly passes through the stator teeth which are located in front of the magnets and almost no flux passes through the stator teeth located in front of the iron poles. In other words, there is no flux leakage from the PM sources to the iron poles flux path. By energizing the DC winding (Fig. 8 (b) to (d)), the flux over the iron pole surfaces increases. It is observed that by increasing the DC current, the flux density in the stator teeth located in front of magnets is altered. It is observed that unlike the conventional machine or case (a) in Fig. 8 where $I_{D C}=0 \mathrm{~A}$, the flux density in the stator teeth is not distributed uniformly and the flux density in each tooth changes along the teeth radial length. This phenomenon arises from flux leakage, which results in the saturation of the stator teeth that limits the torque capability of the machine.

\section{TORQue CAPABILITY COMPARISON AND DISCUSSION}

To quantify the effect of DC current excited flux leakage on maximum torque production of the hybrid machine, the FE models of both topologies are coupled to an external circuit. The torque production capabilities of machines are compared when they are loaded with different phase current. The maximum permissible phase current is $148 \mathrm{~A}$ (rms) corresponding to the current density in the winding of $J=$ $13 \mathrm{~A} / \mathrm{mm}^{2}$. The produced torques are presented in Fig. 9 for the conventional machine and the hybrid machine with different DC excitation values. Based on Fig. 9, the conventional machine is capable of producing an average maximum torque of $100.3 \mathrm{Nm}$, shown with $(-\bullet)$ in Fig. 9, which means that this machine meets the design objective which is having an output power of $42 \mathrm{~kW}$ at $4000 \mathrm{rpm}$.

In a permanent magnet machine it is known that torque is proportional to the length of the machine [24], i.e. $\tau \propto L \times B_{g}$, where $L$ is the length of machine and $B_{g}$ is the air-gap flux density. In the case of the designed hybrid machine without any DC excitation, the air-gap flux density is half of its value for the conventional machine. However, the active length of machines are as the same (26 $\mathrm{mm}$ in both cases). Hence, in theory, one may expect that the torque production capability of hybrid machine in the absence of any DC winding excitation to be half of its potential in comparison with the conventional motor. Based on this theory, the expected produced torque for the hybrid machine with $I_{D C}=0$ Aturns, is

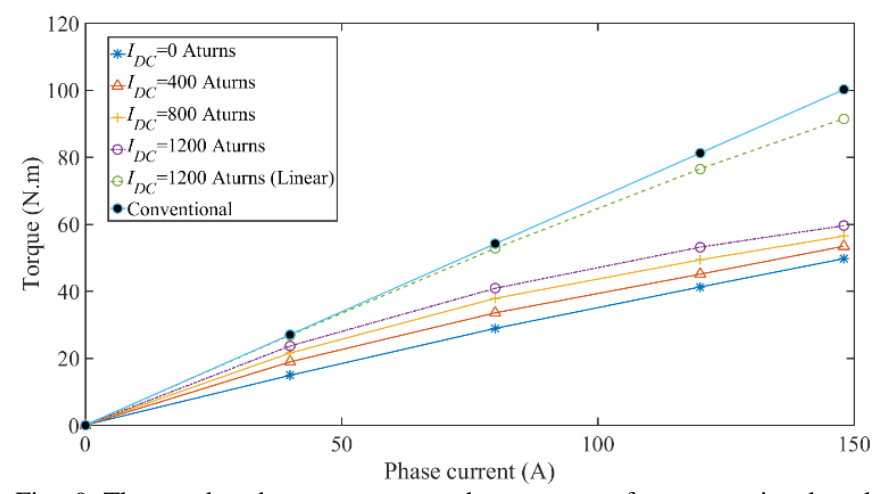

Fig. 9 The produced torque versus phase current for conventional and different DC excitation current in hybrid machine obtained from FE analysis.

50.15 N.m, however, the results obtained from FEA, for the case that $I_{D C}=0$ Aturns shown with (-*), indicates that in this case, the hybrid machine produces 48.6 N.m which is slightly less than the expected value. This $3 \%$ deficiency is due to the axial flux leakage in the hybrid machine. As it is seen from Fig. 7 (a), the profile of the magnetic flux density in the airgap varies along the axial length of machine. By applying the DC current, the air gap flux density increases and consequently the torque production of the hybrid machine is increased, however, the torque does not rise linearly.

In Fig. 9, specifically the curve with the symbols (-o), it is evident that even for $I_{D C}=1200$ Aturns, the hybrid machine only produces $59.3 \mathrm{Nm}$. That is due to the effect of flux leakage and the flux reduction in the stator teeth, which are located in front of the PM poles and also the saturation of the stator teeth in front of iron poles which acts as a flux barrier and limits the torque capability of the machine. To prove the claim that the stator saturation has a limiting impact on the torque production capability of the machine, a sanity check study was carried out by changing the properties of stator lamination: the stator laminations are set to have linear $B-H$ curve characteristics; the results shown in Fig. 9 by (--O); in this case the hybrid machine can produce $89.9 \mathrm{Nm}$ for the maximum permissible phase current of 148 A. Hence, comparing with the produced torque by the hybrid machine with non-linear $B-H$ curve, the output torque has been increased by $33 \%$ which verifies that saturation is the cause of torque reduction. However, the torque production capability of the hybrid machine with the linear material is still below at that of the conventional machine. From Fig. 7 (d), it is seen that although by applying a DC current excitation of $1200 \mathrm{~A}$, the maximum magnetic flux density on the air-gap in front of the iron poles matches the peak value of air-gap flux density in front of PM poles, the shape of flux distribution is different. The average of flux in the air-gap for magnet poles is $0.70 \mathrm{~T}$, whereas this value for iron poles is $0.66 \mathrm{~T}$ and hence the average of air-gap flux density on the hybrid machine for $I_{D C}=1200$ Aturns is $0.68 \mathrm{~T}$. However, from Fig. 4 the flux density of the air-gap in conventional machine is $0.74 \mathrm{~T}$. This indicates the flux leakage in the hybrid machine is responsible for reducing its torque capability in comparison with the conventional topology. This research can be extended to the study of the effect of different parameters such as the pole shapes, DC slot length and depth, etc., on the flux leakage and saturation phenomenon in the hybrid machine. 
TABLE II

PARAMETERS OF THE DESIGNED SURFACE MOUNTED PM MOTOR

\begin{tabular}{l|l|l}
\hline Parameter & $\begin{array}{c}\text { Conventional } \\
\text { Machine } \\
\text { Value }\end{array}$ & $\begin{array}{c}\text { Hybrid } \\
\text { Machine Value } \\
(\text { I } D C=1200 \\
\text { Aturns })\end{array}$ \\
\hline Volume & $0.0016 \mathrm{~m}^{3}$ & $0.0026 \mathrm{~m}^{3}$ \\
\hline Torque density & $61.21 \mathrm{kNm} / \mathrm{m}^{3}$ & $23.03 \mathrm{kNm} / \mathrm{m}^{3}$ \\
\hline $\begin{array}{l}\text { No-load back emf } \\
\text { (peak line-to-line) }\end{array}$ & $252 \mathrm{~V}$ & $236 \mathrm{~V}$ \\
\hline Output power & $42015 \mathrm{~W}$ & $24755 \mathrm{~W}$ \\
\hline
\end{tabular}

Table II compares the performance of the conventional machine with the hybrid machine with non-linear $B-H$ curve characteristics when it is excited with a DC current of $1200 \mathrm{~A}$. The results indicates that the torque density of the conventional machine is almost 2.7 times greater than the torque density of it counterpart hybrid machine when they both have the same active length and maximum air-gap flux density.

\section{CONCLUSION}

In theory, a hybrid consequent pole PM machine and its surface mounted PM machine counterpart of the same active length and cross-section geometry are expected to produce the same torque. However, the side by side comparison between two machines in this paper shows that the hybrid machine produces almost $40 \%$ less torque than the conventional machine. The 3D finite element analysis in this paper reveals some hidden constraints of the hybrid machine, which limits its maximum torque production capability: flux leakage saturates the stator steel in the hybrid machine which for the machine under study in this paper is responsible for around $30 \%$ of the torque production capability reduction. This is validated by showing that the output torque of the machine can be dramatically increased if the stator of the hybrid machine has a linear $B$ - $H$ curve characteristic. Also, it is shown that in the studied hybrid machine, the profile of the flux distribution sourced by DC excitation is different from the flux profile caused by PMs (a distributed flux source, DC winding vs a concentrated flux source, PM). Although it is possible to select the DC excitation such that the flux density from both sources hit the same maximum amplitude, their average values are different. In the case of the studied hybrid machine in this paper, this average air-gap flux difference reduces the torque production capability of the hybrid machine by around $10 \%$. To continue this research and to improve the design process of such hybrid machine, the magnetic flux circuit presented in [21] and [23] needs to be modified by considering the effect of flux leakage and the nonlinear $B-H$ curve characteristic of steel materials.

\section{REFERENCES}

[1] E. K. Dedes, D. A. Hudson and S. R. Turnock, "Assessing the potential of hybrid energy technology to reduce exhaust emissions from global shipping," Energy Policy, vol. 40, pp. 204-218, 2012.

[2] R. D. Geertsma, R. R. Negenborn, K. Vissera and J. J. Hopmana, "Design and control of hybrid power and propulsion systems for smart ships: A review of developments," Applied Energy, vol. 194, pp. 3054, 2017.

[3] N. Bennabi, J. F. Charpentier, H. Menana, J. Y. Billard and P. Genet, "Hybrid propulsion systems for small ships: Context and challenges," in Electrical Machines (ICEM), 2016 XXII International Conference on, Lausanne, Switzerland, 2016.

[4] T. Yang, T. Cox, M. Degano, S. Bozhko and C. Gerada, "History and recent advancements of electric propulsion and integrated electrical power systems for commercial \& naval vessels," International Naval \&Maritime Exhibition and Congress for Latin America, Vina Del Mar, Cile, 2016.

[5] K. Chau and W. li, "Overview of electric machines for electric and hybrid vehicle," International Journal of Vehicle Design , vol. 64, no. 1, pp. 46-70, 2014.

[6] D. Stapersma and H. Woud, "Matching propulsion engine with propulsor," Journal of Marine Engineering \& Technology, vol. 4, no. 2, p. 25032, 2014.

[7] W. P. Symington, A. Belle, H. D. Nguyen and J. R. Binns, "Emerging technologies in marine," Journal of Engineering for the Maritime Environment, vol. 230, no. 1, pp. 187-198, 2016.

[8] V. Somandepalli and K. Marr, "Thermal safety management of lithiumion battery energy storage systems for use in ocean-going and subsea applications," in OCEANS'15 MTS, Washington, USA, 2015.

[9] J. Barry, "Marine Electronics Journal," $16 \quad 12$ 2014. [Online]. Available: www.marineelectronicsjournal.com. [Accessed $02 \quad 02$ 2017].

[10] A. S. Al-Adsani and N. Schofield, "Hybrid permanent magnet generators for electric vehicle applications," in Electric Machines and Drives Conference, 2009. IEMDC '09, Miami, USA, 2009.

[11] C.H. Zhao and Y.-g. Yan, "A review of development of hybrid excitation synchronous machine," in Proceedings of the IEEE International Symposium on Industrial Electronics, Dubrovnik, Croatia, 2005

[12] R. Owen, Z. Q. Zhu, J. B. Wang, D. A. Stone and I. Urquhart, "Review of variable-flux permanent magnet machines," in International Conference on Electrical Machines and Systems (ICEMS) , Beijing, China, 2011.

[13] Y. Amara, L. Vido, M. Gabsi, E. Hoang, A. H. B. Ahmed and M. Lecrivain, "Hybrid Excitation Synchronous Machines: EnergyEfficient Solution for Vehicles Propulsion," IEEE Transactions on Vehicular Technology, vol. 58, no. 5, pp. 2137 - 2149, 2009.

[14] J. F. Gieras, "PM synchronous generators with hybrid excitation systems and voltage control Capabilities: A review," in International Conference on Electrical Machines (ICEM), Marseille, France, 2012.

[15] S. Hlioui, Y. Amara, E. Hoang, M. Lecrivain and M. Gabsi, "Overview of Hybrid Excitation Synchronous Machines Technology," in Conference: Electrical Engineering and Software Applications (ICEESA), Hammamet, Tunisia, 2013.

[16] I. Ozawa, T. Kosaka and N. Matsui, "Less rare-earth magnet-high power density hybrid excitation motor designed for Hybrid Electric Vehicle drives," in 13th European Conference on Power Electronics and Applications, Barcelona, Spain, 2009.

[17] B. Gaussens, E. Hoang, M. Lecrivain, P. Manfe and M. Gabsi, "A new hybrid-excited flux-switching machine with excitation coils in stator slots," in 15th International Conference on Electrical Machines and Systems (ICEMS), Sapporo, Japan, 2012.

[18] S. Li, W. Ding, Y. Hu, T. Wang and S. Yang, "A novel control strategy of hybrid excited flux-switching machine in both constant torque and power range," in 43rd Annual Conference of the IEEE Industrial Electronics Society, Beijing, China, 2017.

[19] N. A. Jafar and E. Sulaiman, "Design analysis of 12S-10P hybridexcitation flux-switching permanent-magnet machines for hybrid electric vehicle," in 8th International Power Engineering and Optimization Conference, Langkawi, Malaysia, 2014.

[20] N. Naoe and T. Fukami, "Trial production of a hybrid excitation type synchronous machine," in IEEE International Electric Machines and Drives Conference, Cambridge,USA, 2001.

[21] J. Tapia, F. Leonardi and T. Lipo, "Consequent-pole permanent-magnet machine with extended field-weakening capability," IEEE 
Transactions on Industry Applications , vol. 39, no. 6, pp. 1704-1709, 2003.

[22] F. Xinghe and Z. Jibin, "Numerical Analysis on the Magnetic Field of Hybrid," IEEE Transactions on Magnetics, vol. 45, no. 10, pp. 45904593, 2009.

[23] J. Tapia, F. Leonardi and T. Lipo, "A design procedure for a PM machine with extended field weakening capability," in 37th IAS Annual Meeting. Conference Record of the Industry Applications Conference, Pittsburgh, USA, 2002.

[24] K. Binns and D. Shimmin, "Relationship between rated torque and size of permanent magnet machines," Electric Power Applications, vol. 143, no. 6, pp. 417 - 422, 1996.

\section{BIOGRAPHIES}

Mehdi Hendijanizadeh received his $\mathrm{PhD}$ in Electromechanical Engineering from University of Southampton U.K in 2014. He then joined ISVR research institute working on nonlinear energy harvesting systems. $\mathrm{He}$ is currently with Mechatronic Research Group at the University of Southampton working on the development of electrical machines tailored for hybrid propulsion applications.

Suleiman M. Sharkh received the B.Eng. and Ph.D. degrees in electrical engineering from the University of Southampton, Southampton, U.K., in 1990 and 1994, respectively. He is Professor of Power Electronics, Machines and Drives, and head of the Mechatronics Research Group at the University of Southampton. He is also the Managing Director of HiT Systems Ltd. He has published over 160 papers in academic journals and conferences. His main research interests are in the area of control, electrical machine and power electronics with applications to electric vehicles, marine propulsion, exhaust energy recovery and submersible pumps. Prof. Sharkh is a senior member of the IEEE, a member of the IET and a Chartered Engineer. He was the 2008 winner of The Engineer Energy Innovation Award for his work on rim driven thrusters and marine turbine generators.

A. Ali. Qazalbash obtained his Master and $\mathrm{PhD}$ degrees in Electrical Engineering from The University of Manchester and University of Southampton U.K in 2004 and 2014 respectively. His employment experience include, National University of Sciences and Technology (NUST) Pakistan, Emerson Industrial automation, UK, Whirlpool Corporation USA, where he worked as electric machine design engineer. 